\title{
Non-autoclaved aerated concrete made of modified binding composition containing supplementary cementitious materials
}

\author{
Oksana Poznyak ${ }^{1}$, Andryy Melnyk ${ }^{2}$ \\ ${ }^{1,2}$ Department of Building Production, Lviv Polytechnic National University, \\ e-mail:1'pozniak@ukr.net,rmelnyk.a@ukr.net
}

Summary: In this paper the impact of carbonate-containing and sulfate components, zeolite, polypropylene fibers on the properties of modified binding composition and nonautoclaved aerated concrete based on them is investigated. The aerated concrete based on the modified binding composition containing a supplementary cementitious material, that of carbonate-containing salt waste, reinforced with polypropylene fibers is characterized by the compressive strength of $2.7 \mathrm{MPa}$ with the density of $650 \mathrm{~kg} / \mathrm{m}^{3}$. The thickness of partitions between pores is $0.16-0.21 \mathrm{~mm}$, and the number of pores with the size $0.2-1.0 \mathrm{~mm}$ is $76.4 \%$.

Keywords: aerated concrete, modified binding composition, wastes, swelling multiplicity, strength, porous structure.

\section{Introduction}

Following the strategy of sustainable development and the principles of the best available technologies application, energy saving in Ukrainian Municipal engineering sector is achieved by constructing energy efficient buildings due to application of efficient building materials. Development of modern building technologies in all technologically advanced countries is aimed at designing cost-effective, efficient materials, the use of which can reduce energy costs and consumption of raw materials [1-3]. Aerated concrete is the optimal material for building because it has wide density and durability ranges, the properties important for solving various construction problems. The increased production of aerated concretes is caused by the increasing demand residential building. Recently, in for construction industry a number of new regulatory documents have been adopted, aimed at reducing energy and raw materials consumption and improving quality and reliability of construction. Extensive use of non-autoclaved aerated concrete is one of the ways to increase (improve) thermal properties of external building constructions in Ukraine. Research and practice in the field of aerated concretes are aimed at improving product quality simultaneously reducing the cost of products [4-7].

Aerated concrete in which air-voids are entrapped in the mortar matrix by means of a suitable aerating agent is produced from cement or lime, silica sand and sometimes pozzolanic materials and classified as lightweight concrete. Based on the method of poreformation, it is classified into three groups: air-entraining method (gas concrete), foaming method (foamed concrete) and combined method. Aerated concrete can be non-autoclaved (NAAC) or autoclaved (AAC) based on the method of curing. The compressive strength, drying shrinkage, absorption properties etc. directly depend on the method and duration of curing. Once it is cured enough, the concrete foam is stripped from its mold, sliced into blocks or slabs of the required size [8]. 
Improving physical and mechanical properties of aerated concretes due the application of modified binding composition containing supplementary cementitious materials that change properties of partitions between pores is a relevant problem of nowadays. The use of industrial wastes is of practical importance for building materials technology in general, and aerated concretes technology, in particular, because it allows improving the basic material properties and increasing technical and economic performance; it will also improve ecology of the environment by recycling industrial wastes [4, 8-11]. It is relevant to create the binding compositions that allow obtaining aerated concretes of improved performance quality with minimum production costs.

\section{Materials and methods}

In experimental studies, Portland cement CEM I - 42,5R JSC "IvanoFrankivskcement" with the following characteristics: specific surface $S_{\text {spec }}=350 \mathrm{~m}^{2} / \mathrm{kg}$; residue on the sieve № $008-1.1 \%$; initial setting time - $3 \mathrm{~h} 10 \mathrm{~min}$.; end of hardening $-4 \mathrm{~h}$ 50 min., was used. Fly ash from Burshtynska thermal power plant was used as a finely dispersed filler with the following properties: true density $-2.21 \mathrm{~g} / \mathrm{cm}^{3}$; bulk density -870 $\mathrm{kg} / \mathrm{m}^{3}$; residue on sieve № 008 - 8.7 mass.\%; chemical composition, mass.\%: $\mathrm{SiO}_{2}-54$; $\mathrm{Al}_{2} \mathrm{O}_{3}-23.75 ; \mathrm{Fe}_{2} \mathrm{O}_{3}+\mathrm{FeO}-13.8 ; \mathrm{MgO}-1.91 ; \mathrm{CaO}-4.98 ; \mathrm{SO}_{3}-0.53 ; \mathrm{K}_{2} \mathrm{O}+\mathrm{Na}_{2} \mathrm{O}-$ 0.25 . As supplementary cementitious materials, salt processing wastes were used, such as carbonate-containing and sulfate components and clinoptilolite type of natural zeolitic tuff of Sokyrnytsia deposit, Zakarpattia region of the Ukraine with the following chemical composition, mass.\%: carbonate-containing component (CW): $\mathrm{SiO}_{2}-1.8, \mathrm{Al}_{2} \mathrm{O}_{3}-1.64$, $\mathrm{Fe}_{2} \mathrm{O}_{3}-0.54, \mathrm{CaO}-39.42, \mathrm{MgO}-4.21, \mathrm{Na}_{2} \mathrm{O}-6.42, \mathrm{~K}_{2} \mathrm{O}-6.57$; sulfate component (SW): $\mathrm{SiO}_{2}-0.85, \mathrm{Al}_{2} \mathrm{O}_{3}-1.01, \mathrm{Fe}_{2} \mathrm{O}_{3}-0.14, \mathrm{CaO}-31.47, \mathrm{MgO}-1.38, \mathrm{Na}_{2} \mathrm{O}$ - 2.85, $\mathrm{K}_{2} \mathrm{O}$ - 35.9; zeolitic tuff $(\mathrm{Ze}): \mathrm{SiO}_{2}-69.21, \mathrm{Al}_{2} \mathrm{O}_{3}-11.75, \mathrm{Fe}_{2} \mathrm{O}_{3}-1.61, \mathrm{CaO}-1.90, \mathrm{MgO}-1.10, \mathrm{Na}_{2} \mathrm{O}$ - 2.65, $\mathrm{K}_{2} \mathrm{O}-3.52$. Physical and mechanical properties of cementitious systems and aerated concretes based on them were tested by standard test methods.

\section{Results and discussion}

\subsection{Investigation of binding composition}

An important technological feature of aerated concretes production aimed at providing the necessary average density and strength is a design of optimal conditions for two processes that occur simultaneously: gas release and hardening of aerated concrete mix. It is important to correlate the speed of gas release with that of aerated concrete hardening. Before setting the "cement - water" system, the process of gas release must be over.

The experimental studies of the effect of adding cementitious materials on the setting time of binding composition showed that including carbonate-containing waste of salt processing in the amount of 10 mass.\% into the binding composition accelerates the setting time (Fig.1).

The initial setting time of such a system is $130 \mathrm{~min}$. while that for Portland cement is 190 min.; the finish setting times binding composition containing carbonate wastes is 210 min., whereas for ordinary Portland cement finish setting time $290 \mathrm{~min}$. Adding sulfate salt wastes to the binding composition reduces the time of its initial setting time by $30 \mathrm{~min}$., the finish setting time is reduced by $20 \mathrm{~min}$., comparison to those for Portland cement. Setting time delay was observed with the introduction of 10 mass.\% zeolite. The initial setting time is $270 \mathrm{~min}$, finish setting time - $340 \mathrm{~min}$. 


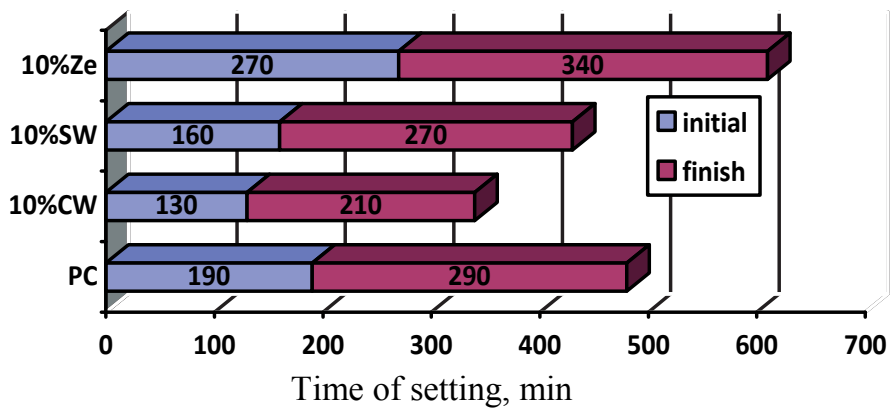

Fig. 1. The effect of adding of supplementary cementitious materials on the setting time of binding composition

To approximate conditions of aerated concrete production, testing of cement paste was carried out at $\mathrm{W} / \mathrm{C}=0.41$, which provides flowing of concrete mixture of $190 \mathrm{~mm}$. The effect of adding cementitious materials on the strength of binding composition is presented in fig 2.

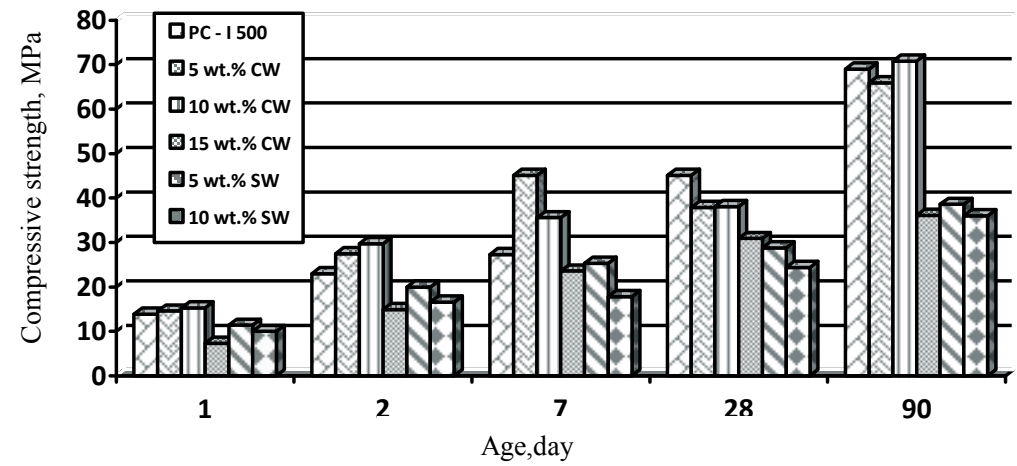

Fig. 2. The effect of carbonate-containing wastes $(\mathrm{CW})$ and sulfate-containing wastes $(\mathrm{SW})$ on the strength of binding composition

After adding 5 mass.\% of carbonate-containing waste to the binding composition, its strength increases from 13.9 $\mathrm{MPa}$ to $14.6 \mathrm{MPa}$ after one day of hardening in normal conditions (technical effect $\Delta \mathrm{R}=5.1 \%$ ). After adding 10 mass.\% of carbonate-containing waste to the binding composition, its strength increases to $15.3 \mathrm{MPa}(\Delta \mathrm{R}=10.1 \%)$. The further increase of the carbonate-containing waste amount to 15 mass.\% reduces the cement stone strength to $7.3 \mathrm{MPa}$. During longer time of hardening the highest level of strength is shown by the cement stone including 10 mass. $\%$ of carbonate-containing salt wastes. Thus, the strength of the cement stone on the basis of the binding composition after 90 days of hardening is $70.8 \mathrm{MPa}$, while the strength of the cement stone based on Portland cement CEM I - 42,5R is $69.0 \mathrm{MPa}$.

The research on the sulfate wastes effect on binding composition properties has shown that introducing sulfate-containing components to the composition of binding composition causes a decrease of the cement stone strength during all periods of hardening. Thus, after adding 5 mass. $\%$ of sulfate-containing components to the binding composition, its strength decreases by $18.3 \%$ after 1 day of hardening, after 7 days by $7.3 \%$, and after 28 days by $36.1 \%$. Further increase of sulfate component amount in the binding composition to 10 
mass. $\%$ leads to the drop in its strength by $27.9 \%$ after 1 day, by $34.8 \%$ after 7 days, and by $45.9 \%$ after 28 days.

The modeling systems such as "Ca(OH $)_{2}$ - aluminum paste", "Ca(OH) 2 - carbonatecontaining waste - aluminum paste" which hardened in normal conditions and after heat treatment were investigated in terms of the processes of structure formation partitions between pores in aerated concrete based on modified binding composition. Currently the big amount of aerated concrete is produced by using autoclaves that increase the costs of energy and the material. According to X-ray diffraction analysis of stone based on the model system of "Ca(OH) $)_{2}$ - aluminum paste" which was cured under normal conditions, lines of portlandite $(\mathrm{d} / \mathrm{n}=0,493 ; 0,263 ; 0,193 \mathrm{~nm})$ and metastable hexagonal hydroaluminates calcium $4 \mathrm{CaO} \cdot \mathrm{Al}_{2} \mathrm{O}_{3} \bullet 19 \mathrm{H}_{2} \mathrm{O}(\mathrm{d} / \mathrm{n}=1,06 ; 0,532 ; 0,288 \mathrm{~nm})$ are fixed in all times of hardening.

The investigations of structure formation processes in a model system of " $\mathrm{Ca}(\mathrm{OH})_{2}$ aluminum paste" after heat treatment showed that there is a conversion of metastable hexagonal calcium hydroaluminate $4 \mathrm{CaO} \cdot \mathrm{Al}_{2} \mathrm{O}_{3} \bullet 19 \mathrm{H}_{2} \mathrm{O}$ in to stable hydrated phase - cubic calcium hydroaluminate $3 \mathrm{CaO} \cdot \mathrm{Al}_{2} \mathrm{O}_{3} \cdot 6 \mathrm{H}_{2} \mathrm{O}(\mathrm{d} / \mathrm{n}=0,2286 ; 0,255 ; 0,442 ; 0,510 \mathrm{~nm})$, which is accompanied by a change in hardened system volume.

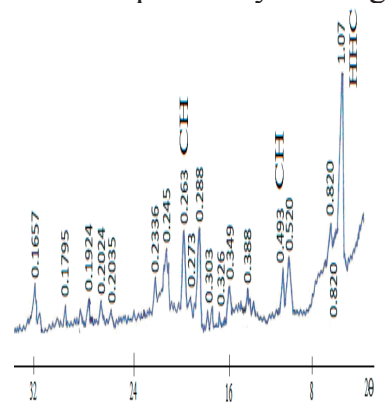

a

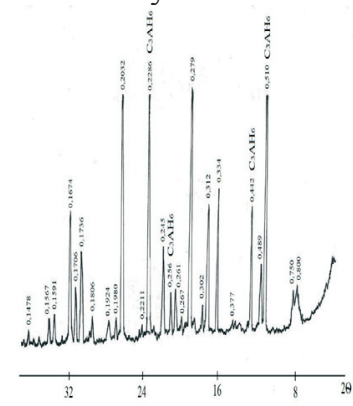

b

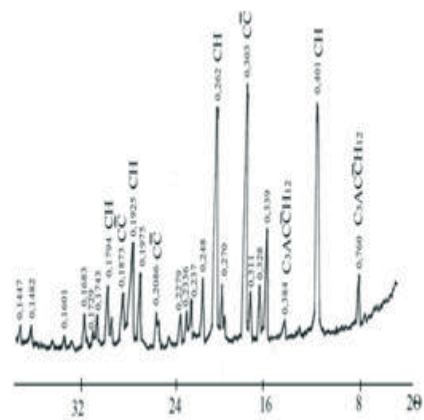

c

Fig. 3. XRD patterns of model system: „Ca(OH $)_{2}$ - aluminum paste”, hydrated under normal conditions (a) and after heat treatment $(\mathrm{b}),{ }_{\text {, }} \mathrm{Ca}(\mathrm{OH})_{2}$ - waste product - aluminum paste” (c)

According to X-ray diffraction analysis of model system of $" \mathrm{Ca}(\mathrm{OH})_{2}$ - carbonatecontaining - aluminum paste" the use of carbonate waste product from processing of salt production as a supplementary cementitious material provides replacement of the hexagonal calcium hydroaluminates in the presence of $\mathrm{CaCO}_{3}$ by more stable hydrocarboaluminates $3 \mathrm{CaO} \cdot \mathrm{Al}_{2} \mathrm{O}_{3} \cdot \mathrm{CaCO}_{3} \cdot 12 \mathrm{H}_{2} \mathrm{O}(\mathrm{d} / \mathrm{n}=0,760 ; 0,380 \mathrm{~nm})$, whose structure role increases with time. Furthermore, there are lines of calcium carbonate $(\mathrm{d} / \mathrm{n}=0,303 ; 0,227 ; 0,208 \mathrm{~nm})$ and portlandite $(\mathrm{d} / \mathrm{n}=0,493 ; 0,263 ; 0,193 \mathrm{~nm})$ on diffractograms.

\subsection{The non-autoclaved aerated concrete properties}

To obtain products with necessary strength and average density, the technology of non-autoclaved aerated concrete production must have an important characteristic swelling multiplicity, which later defines the characteristics of the aerated concrete. Aerated concrete mixes based on Portland cement have the swelling time of $21 \mathrm{~min}$. (fig. 4).

After adding 10 mass. $\%$ of carbonate-containing salt waste the reduction of the concrete array swelling time to 12-14 minutes is observed, after adding a sulfate component, the time reduces to $9-11 \mathrm{~min}$. It should be noted that multiplicity of swelling of the aerated concrete mix on the basis of the modified binding composition including carbonate- 
containing salt wastes is 2.9 , that including sulfate wastes is 2.3 , while the multiplicity of swelling of aerated concrete mix based on Portland cement is 2.8 .

A modified binding composition containing zeolite, is characterized by swelling time of $11 \mathrm{~min}$, and the multiplicity of swelling 1.82, which does not allow obtaining the necessary density of aerated concrete.

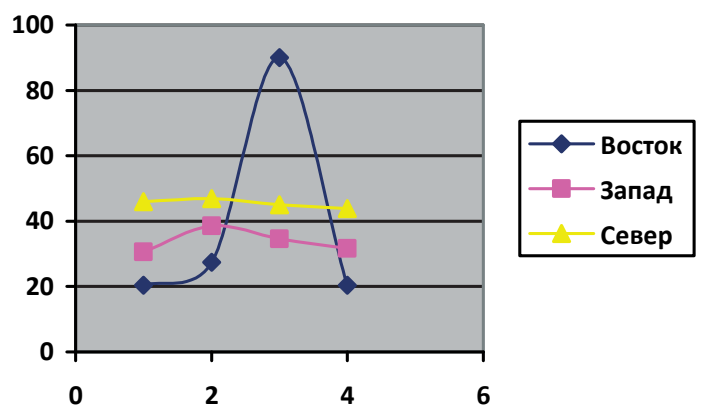

Fig. 4. Swelling kinetics of aerated concrete mixtures

The experimental studies showed the effects of carbonate-containing salt wastes and sulfate salt wastes on strength characteristics of aerated concretes. As shown in Fig. 5, the addition of salt wastes allows improving the strength of aerated concrete during all periods of concrete hardening.

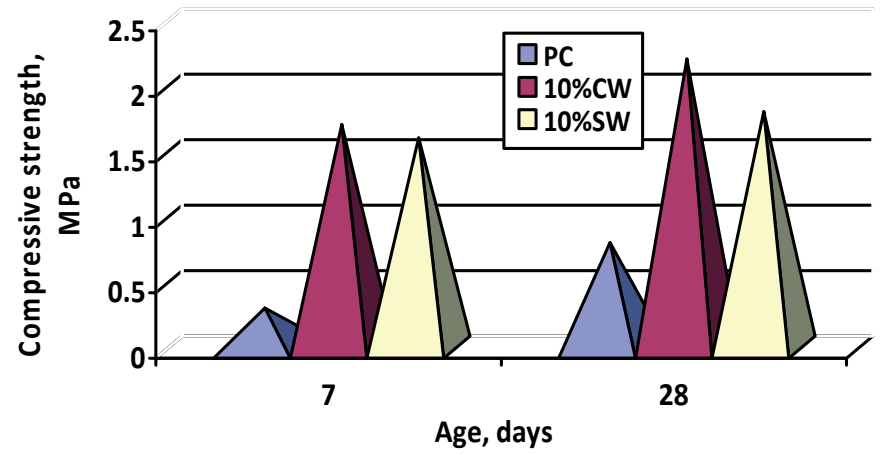

Fig. 5. The effect of salt processing wastes on compressive strength of aerated concrete

Thus, non-autoclaved aerated concrete with carbonate-containing salt waste is characterized by the strength of $1.7 \mathrm{MPa}$ (technical effect $\Delta \mathrm{R}=466 \%$ ) after 7 days of hardening, average density of $650 \mathrm{~kg} / \mathrm{m}^{3}$, while the strength of aerated concrete based on Portland cement is $0.3 \mathrm{MPa}$. After adding the sulfate component, the increase of the aerated concrete strength to $1.6 \mathrm{MPa}(\Delta \mathrm{R}=433 \%)$ is observed. After 28 days of hardening, the aerated concrete based on the modified cementitious system that includes carbonate-containing salt wastes has the strength of $2.2 \mathrm{MPa}$ (technical effect $\Delta \mathrm{R}=175 \%$ ), whereas the compressive strength of the aerated concrete based on ordinary Portland cement is $0.8 \mathrm{MPa}$. It should be noted that after adding a sulfate component the aerated concrete mixture cures quickly, simultaneously increasing the density of aerated concrete, and therefore its strength. Aerated concrete with sulfate additives after 28 days of hardening has the compressive strength of $1.8 \mathrm{MPa}$, but its density is $715 \mathrm{~kg} / \mathrm{m}^{3}$. 
According to optical microscopy data in aerated concrete on the basis of ordinary Portland cement the prevailing pores have the size of 1.1-2.2 $\mathrm{mm}$, the number of them reaching $61 \%$. In aerated concrete the number of pores having the size of $0.2-1.0 \mathrm{~mm}$ increases from $23.5 \%$ to $76.4 \%$, when the modified binding composition including carbonate-containing salt wastes is used.

By the method of scanning electron microscopy carbonate crystals, plastic crystals of calcium hydroaluminates, and hydrocalumite in the structure partitions between pores of non-autoclaved aerated concrete which includes carbonate-containing salt wastes are observed (Fig. 6). The presence of these crystals in the structure of aerated concrete provides compression of microstructure of partitions between pores and this causes the increase of strength characteristics of the finished products. Thickness of partitions between pores is $0.16-0.21 \mathrm{~mm}$.
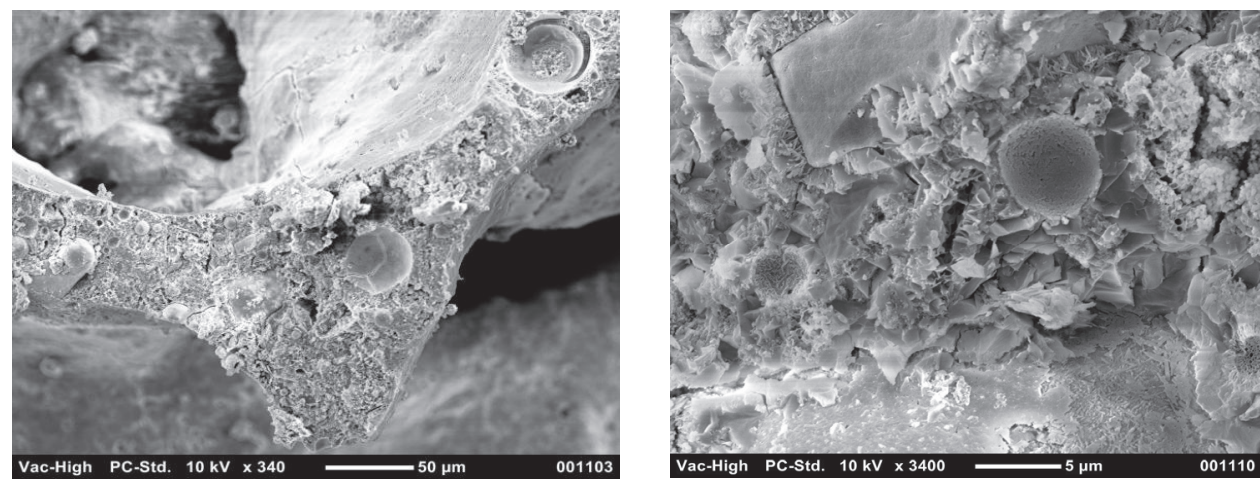

Fig. 6. Microstructure of partitions between pores of aerated concrete based on modified cementitious systems with carbonate-containing wastes

Obtained by scanning electron microscopy, results are confirmed by X-ray diffraction analysis. Thus, after adding carbonate-containing salt wastes into the composition of aerated concrete, the X-ray diffraction pattern characterized by intense lines of hydrocalumite $\mathrm{Ca}_{4} \mathrm{Al}_{2}(\mathrm{OH})_{14} \cdot 6 \mathrm{H}_{2} \mathrm{O}(\mathrm{d} / \mathrm{n}=0.820 ; 0.388 ; 0.288 ; 0.245 \mathrm{~nm})$ that belongs to the group of aqueous hydroxides may contain in its lattice a significant amount of anion $\mathrm{CO}_{3}{ }^{2-}$. It should be noted the addition of the sulfate salt waste into the composition of the binding composition provides acceleration of Portland cement hydration in the early stages of hardening. Thus, after 2 days of hardening, the hydration degree of the modified binding composition containing carbonate-containing salt wastes is $49.9 \%$, whereas the hydration degree of Portland cement is $23.7 \%$.

Regardless of the adopted technology, as well as conditions and regime of hardening, the traditional disadvantages of aerated concretes are low resistance to tensile stresses and increased fragility. Non-autoclaved aerated concretes are characterized by high shrinkage strains, leading to intense fracture formation and even destruction of products [4]. Fiber reinforcement significantly reduces or completely eliminates the appearance and development of shrinkage cracks during hardening and further use of the material.

Experimental studies prove that the addition of the polypropylene fiber into aerated concrete does not affect kinetics of concrete array swelling. Thus, swelling multiplicity of aerated concrete without any reinforcing component in its composition is 2.83 , whereas the aerated concrete mix containing $0.1 \mathrm{~kg}$ of polypropylene fiber is characterized by swelling multiplicity of 2.78. The increase of the fiber content does not affect kinetics of gas release and growth of aerated concrete mix. 
The results of experimental studies show (Table 1) that using reinforcing fibers in the composition of aerated concretes based on a modified binding composition containing supplementary cementitious materials in the form of salt processing wastes enhances the strength of non-autoclaved aerated concretes.

Table 1. Effect of polypropylene fiber on the strength characteristics of aerated concrete

\begin{tabular}{ccc}
\hline Type and content of additives & Compressive strength, MPa, after days of hardening \\
\cline { 2 - 3 } & 7 & 28 \\
\hline- & 0,3 & 0,8 \\
\hline $10 \% \mathrm{CW}$ & 1,8 & 2,2 \\
\hline $10 \% \mathrm{CW}+$ fiber & 2,2 & 2,7 \\
\hline $10 \% \mathrm{SW}+$ fiber & 1,6 & 1,8 \\
\hline $10 \% \mathrm{SW}+$ fiber & 1,9 & 2,2 \\
\hline
\end{tabular}

After 28 days of hardening, the strength of aerated concrete containing carbonatecontaining salt wastes with the inclusion of polypropylene fiber increases from $2.2 \mathrm{MPa}$ to 2.7 $\mathrm{MPa}$, whereas the strength of such a concrete containing sulfate salt waste increases from 1.8 $\mathrm{MPa}$ to $2.2 \mathrm{MPa}$ respectively.

\section{Conclusions}

The use of salt processing wastes, on one hand, has a positive ecological effect as wastes are recycled; and, on the other hand, it has economic and technical effects. Including up to 10 mass.\% of carbonate-containing salt wastes into binding composition provides the increase of cement stone early strength as well as that of later terms of hardening; and the use of sulfate-containing wastes causes decrease of mechanical strength at all terms of hardening. Aerated concretes containing carbonate-containing salt wastes have better ability to retain gas, the evidence of which is shortening the time of aerated concrete mix growth from $21 \mathrm{~min}$. to $12-14 \mathrm{~min}$. and increasing the multiplicity of swelling on $5 \%$. The addition of reinforcing components to the composition of aerated concretes, polypropylene fiber, in particular, improves the strength characteristics of aerated concretes. The aerated concrete based on the modified binding composition containing a supplementary cementitious material, which is carbonate-containing salt waste, and reinforced with polypropylene fibers is characterized by the compressive strength of $2.7 \mathrm{MPa}$ with the density of $650 \mathrm{~kg} / \mathrm{m}^{3}$ after 28 days of hardening. The thickness of partitions between pores is $0.16-0.21 \mathrm{~mm}$, and the number of pores with the size $0.2-1.0 \mathrm{~mm}$ is $76.4 \%$.

\section{Acknowledgement}

This research was financed by the Project $N^{0}$ IPBU.01.01.00-06-570/11-00.

\section{References}

1 Sanytsky M.A., Pozniak O.R., Marushchak U.D. Energy saving technologies in building. - Lviv: Lviv Polytechnic Publishing House, 2013 - 236 p.

2 Kryvenko P.V., Petropavlovskyy O.N., Gelevera O.H. Cement with a high content of mineral supplements , natural and anthropogenic // Construction of Ukraine. - 2006. - № 1 - P. 39-45.

3 Narayanan N., Ramamurthy K. Structure and properties of aerated concrete: a review // Cement \& Concrete Composites 22 (2000) 321-329.

4 Zaharchenko P.V., Scherbyna N. Improving to create capabilities pores of aerated concrete mixture through the use of industrial waste // Construction materials and sanitary equipment. - K.: SC NDIBMV, 2007. - № 25. - P. 46-47. 
5 Serduk V.R., Mishchenko A. Mineral and chemical additives in the technology of aerated concretes // Construction materials and sanitary equipment. - 2011. - № 39. - P. 141-146.

6 Lapovskaya S.D. Aerated fiber - composite materials for construction // Construction materials and sanitary equipment. - 2009. - № 32. - P.25-29.

7 Martynov V.I., Broken V.N., Martynov E.V., Orlov D.A., Vetoh A.M. Theoretical control of properties of aerated concrete and experimental verification // News Odessa State Academy of Construction and Architecture. - Odessa : Zovnishreklamservis. - 2007. - № 25. - P. 205-211.

8 Tanacan L., Ersoy H., Arpacioglu U. Effect of high temperature and cooling conditions on aerated concrete properties // Construction and Building Materials 23 (2009). - P. 1240-1248.

9 Karakurt C., Kurama H., Topcu B. Utilization of natural zeolite in aerated concrete production // Cement \& Concrete Composites 32 (2010) 1-8.

10 Just A., Middendorf B. Microstructure of high-strength foam concrete // Materials Characterization 60 (2009)741- 748.

11 Kearsley E.P., Wainwright P.J. The effect of porosity on the strength of foamed concrete // Cement and Concrete Research 32 (2002) 233-239. 